Highlights:

- 20 rater moves which are used in rater negotiations to resolve rater discrepancy have been identified and validated.

- Systematic examination of rater negotiations has been made possible with the Rater Negotiation Scheme (RNS).

- The duration of rater negotiations and the variety of argumentative moves involved in them varied depending on the context. 
Title Page (with Author Details including unblinded version of

source file)

\title{
Rater Negotiation Scheme: How writing raters resolve score discrepancies
}

Ece Sevgi-Sole ${ }^{\mathrm{a}}$, Aylin Ünaldı ${ }^{\mathrm{b}}$

\begin{abstract}
In practices of direct assessment of writing ability, the variability of human decision-making during scoring poses great challenges to the validity of assessment (Kane, 2006). The variables causing differences in individual raters' scoring interpretations have been widely investigated (e.g. Eckes, 2012; Wolfe et.al, 2016). However, the issue of how raters negotiate to resolve discrepancies has not received attention although rater negotiation is a widely used score resolution method. As it has been emphasized by scholars interested in the argumentative behavior of raters (e.g. Trace et. al., 2017), a systematic analysis of score negotiations will enable us to analyze the dependability of score negotiations. The purpose of this study is twofold: to present a thorough analysis of the argumentative structure of rater discrepancy resolution discussions with a view to understanding their underlying dynamics, and to investigate whether the elements of the argumentative structure of negotiations differ from research settings to authentic score resolution practices. In line with this aim, rater negotiations following a written test at the language school of an English-medium university were analyzed within the framework of Argumentation Theory by Toulmin (1958) and Walton (2005, 2016). The negotiation data were obtained from 99 recorded rater discussions among 30 EFL teachers, and transcribed, coded and categorized into argumentative discussion moves. A Rater Negotiation Scheme (RNS) was developed through a recursive data analysis and categorization process, and it was validated through field-testing in authentic settings. The findings have implications both for research on rater negotiations and arguments on the reliability of the method.
\end{abstract}

Key words: writing assessment, rater negotiations, discrepancy resolution, validity in performance assessment, Rater Negotiation Scheme

This research did not receive any specific grant from funding agencies in the public, commercial, or not-for-profit sectors.

\footnotetext{
${ }^{a}$ Corresponding author. University of Milan, SLAM Via Festa del Perdono, 11, 20122 MI , ITALY ecesevgi@gmail.com +393480096505

b University of Huddersfield, 10 Queensgate Huddersfield, United Kingdom a.unaldi@hud.ac.uk
} 


\title{
Rater Negotiation Scheme: How writing raters resolve score discrepancies
}

\author{
ABSTRACT \\ In practices of direct assessment of writing ability, the variability of human decision-making during \\ scoring poses great challenges to the validity of assessment (Kane, 2006). The variables causing \\ differences in individual raters' scoring interpretations have been widely investigated (e.g. Eckes, \\ 2012; Wolfe et.al, 2016). However, the issue of how raters negotiate to resolve discrepancies has \\ not received attention although rater negotiation is a widely used score resolution method. As it has \\ been emphasized by scholars interested in the argumentative behavior of raters (e.g. Trace et. al., \\ 2017), a systematic analysis of score negotiations will enable us to analyze the dependability of \\ score negotiations. The purpose of this study is twofold: to present a thorough analysis of the \\ argumentative structure of rater discrepancy resolution discussions with a view to understanding \\ their underlying dynamics, and to investigate whether the elements of the argumentative structure of \\ negotiations differ from research settings to authentic score resolution practices. In line with this \\ aim, rater negotiations following a written test at the language school of an English-medium \\ university were analyzed within the framework of Argumentation Theory by Toulmin (1958) and \\ Walton $(2005,2016)$. The negotiation data were obtained from 99 recorded rater discussions among \\ 30 EFL teachers, and transcribed, coded and categorized into argumentative discussion moves. A \\ Rater Negotiation Scheme (RNS) was developed through a recursive data analysis and \\ categorization process, and it was validated through field-testing in authentic settings. The findings \\ have implications both for research on rater negotiations and arguments on the reliability of the \\ method.
}

Key words: writing assessment, rater negotiations, discrepancy resolution, validity in performance assessment, Rater Negotiation Scheme 


\section{Introduction}

The use of human decision-making in direct assessment of writing practices has long been discussed as a challenge to the validity of the scoring decisions (Trace, Meier \& Janssen, 2017). In Messick's (1993) terms, lack of similarity of the scores assigned on the same test taker essay by different raters would hint at the existence of construct-irrelevant variance. A wide range of construct-irrelevant factors- from the rater's background or experience to the quality of the test taker's handwriting - might make the scoring decision on a particular essay relatively lenient or harsh. In an attempt to explain the decision-making processes of raters, several models of rater cognition have been proposed (Freedman \& Calfee, 1983; Cumming, 1990; Wolfe, 1997). These models have helped to conceptualize the processes involved in essay scoring, and to determine how differences in these may lead to raters' different interpretations of the same scoring task. These variables have been determined as rater bias and rater effects (Lumley, 2005; Barkaoui, 2010; Eckes, 2012; Wolfe et.al, 2016).

Current approaches in language assessment define validity as an argument concerning the extent to which test interpretations and uses can be justified (Kane, 2006, 2012; Chapelle, 2012). The validity as an argument approach takes score assignment as a component of scoring inference (Kane, 2012, 2013). Kane (2013) underlines three desirable aspects of scoring to warrant validity claims: appropriacy of scoring procedures, application of scoring procedures as intended; and unbiased scoring. Kane's (2006) definition of appropriateness concerns how efficiently the expert raters can determine the scoring categories which delineate the construct. Therefore, congruent interpretation of test taker performance is a key issue in achieving validity in contexts of performance assessment. It is also emphasized that the betterment of rater training procedures, scoring guidelines and procedures in line with the appropriateness principle increases efficiency in 
scoring. Besides, rater bias should be checked through the use of appropriate statistical procedures (Kane, 2006).

While the variables causing differences in raters' scoring interpretations have been widely investigated on the basis of individual raters, the issue of how raters resolve discrepancies when they have to agree on a score has not received attention. More specifically, discursive processes that raters go through during score negotiations have not been investigated or analyzed before, although such an analysis may potentially provide us with deeper insight into the dynamics of writing scoring.

Score negotiations include explicit expressions of interpretations of test taker performance, claims raised based on these interpretations and a range of decisions made on the attributes of test takers. These discursive processes construct a persuasive argumentation in which each rater seeks to convince the other on the plausibility of their claim based on the evidence from test performance, scale attributes and any relevant aspect of assessment. A systematic analysis of argumentative discursive moves involved in score negotiations will enable us to understand interpretative processes of raters in more detail and to analyze how they develop, sustain and change their arguments. The amount and range of evidence that raters use in supporting their arguments, refuting the arguments of the other or accepting them are issues closely related with the quality, and hence, the efficacy of score negotiations. The need for such an analysis has been emphasized by scholars interested in the argumentative behavior of raters in score negotiations (e.g. Trace et. al., 2017). It is also important to know whether the dynamics of score negotiations change according to contextual conditions such as time restrictions in order to argue for the consistency, thus, the reliability of this method of discrepancy resolution. The current study aims at filling this gap in writing assessment literature by first identifying the characteristics of score negotiation discussions and then comparing the nature of score negotiations in a research setting and in an authentic exam setting. Two research questions given below will be investigated: 
1) What are the discursive moves used by raters in score resolution discussions?

2) Does the nature of score negotiation differ according to the context? 


\section{Literature review}

Although efficacy of score negotiations as a method of discrepancy resolution is an issue of validity, research investigating how raters resolve their disagreement on score interpretations through negotiations is scarce. Most studies in the field focus on the outcome of different methods of discrepancy resolution, while studies investigating whether the process includes a coherent and complete co-construction of score interpretations are rare. This study aims at analyzing score negotiations, situating them in an argumentation framework in order to investigate their nature. Thus, this section presents a review of studies on rater discrepancy resolutions followed by a review of relevant theories of argumentation.

\subsection{Rater discrepancy resolutions}

As one of the important studies on score negotiations, Johnson, Penny, Gordon, Shumate, and Fisher (2005) propose four models for score resolution to be used in cases of rater discrepancy: 1) parity model, where a third scorer is included and the three scores obtained are averaged; 2) tertium quid model, where the score of the third rater, presumably the expert, and that of the two already assigned scores which is closer to the expert's are summed up and averaged; 3) expert judgment model, where the expert rater has the final word and assigns the operational score; and 4) discussion model, where two scorers whose initial scores do not agree come together to reach an agreement without the presence of an expert rater. Johnson et al (2005) investigate whether discussion improves the accuracy of scores in comparison to the method of averaging the initial scores in order to resolve score differences. Their findings suggest a positive contribution of rater discussions to score accuracy. Based on this positive effect, rater negotiation is proposed as an effective method for score resolution.

Johnson et al. (2005) also investigate whether the raters engage in the resolution process equally or whether the use of rater discussion gives one of the raters the opportunity to dominate the other. 
Equal participation of each rater in the discussion is taken as evidence of an effective discussion while the dominance of one of the raters throughout this process might be evaluated as a threat to final score accuracy. No significant rater dominance during the discussions is reported. However, it is also indicated in the study that two raters showing equal participation and finally reaching a consensus would not mean that the consensus reflects a true score.

Trace, Janssen and Meier (2017) take up a socio-cultural approach towards rater negotiation discussions and view these discussions as a resource for raters to co-construct their interpretations of the construct being measured. With this purpose in mind, Trace et al (2017) analyze purposefully sampled parts of data from six-rater negotiation sessions in which raters discuss scores for language and organization of the essays- the two categories that produce the largest number of discrepancies. The sampled data are analyzed to identify the emerging themes and to focus on the instances where the raters build on each other's ideas and co-construct their understanding of rubric categories. The instances in which the raters echo each other's language to show acknowledgement of the other rater's values are also taken as an indication of shared values by the raters. The results indicate that raters use shared terminology through negotiation, and co-construct justifications to clarify the ambiguities in their understanding of the construct. Johnson et al (2005) and Trace et al (2017) have made a substantial contribution to our understanding of rater negotiation. Our study aims at building on them with a detailed analysis of the dynamic verbal exchanges between raters and to identify the argumentative moves raters make to justify their position in score negotiations. This will help to specify the inferences and supporting assumptions based on test responses and relate them to score interpretations in discrepancy resolutions (Kane, 2013)

\subsection{Theories of argumentation}

Approaching rater negotiations from the validity perspective necessitates a solid theoretical standpoint which will enable empirical investigation and analysis of rater negotiations. As a matter of fact, argumentation theories form a link between argument-based approach to validation and 
discrepancy negotiations in language assessment as an example of persuasive dialogue. For example, the Argumentation Theory by Toulmin (1958) determines claim, ground data, counterclaim, backing, warrant, and rebuttal as components of an argument. This resonates with the validity framework suggested by Kane (2013) for the evaluation of plausibility and appropriateness of interpretations and assumptions about test takers' performance.

On the other hand, Walton's $(1998,2016)$ Theory of Dialogic Argumentation designates the concept of "moves in an argument", and his categorization of dialogue types is applicable in the categorization of raters' discrepancy negotiations as a "persuasion dialogue". For this reason, it is important to briefly revisit the basic components of the relevant argumentation theory at this point.

Walton (2005, p.2) defines dialogue as "a type of goal-directed conversation in which two participants (in the minimal case) are participating by taking turns". He calls each turn taken to respond to the previous statement $a$ move, which means that this perception of a dialogue is actually an interacting chain of discursive moves. According to Walton (2005), an argumentative dialogue involves two opposing claims put forward by the participants. In the course of the dialogue, each participant makes a series of moves. Some of these moves may support their own standpoint, either by putting forward statements to eliminate any doubt on their partner's part, or by refuting the reactions provided by their partners. When the argumentation provided is not found convincing enough by the other party, further argumentation follows. Each move that supports its owner's view is added to its owner's commitment set. The term commitment was initially coined by Hamblin (1971) and has been used within the framework of the dialogue theory, which analyzes the set of moves recorded in a dialogue and the rules governing their interaction. At the end of the discussion, one of the standpoints should be accepted by both parties, and the opposing viewpoint must be retracted. The retracted viewpoint is deleted from its presenter's commitment set, and the winner of an argument is the one whose point of view is largely accepted by the other party (Walton, 2005). 
The collective goal of the dialogue determines its type as well as the types of moves the participants are likely to make. In order to analyze the participant moves in a dialogue, the goal of the dialogue, and the goals of the individual participants should be made clear. According to Walton and Krabbe's (1995) categorization of dialogues, in persuasion dialogues the aim is to reach a stable agreement between the discussants, at least one of whom will eventually have to change their point of view to resolve the conflict of opinion. This definition enables us to take raters' discrepancy resolution negotiations as persuasion dialogues in this study.

Coined by Walton (1989), the term 'persuasion dialogue' has been used to study dialogues most dominantly in the fields of law, and more recently in artificial intelligence (AI), as in the case of Prakken (2006). Prakken's analysis of persuasion dialogue emphasizes the typical features of persuasion and the moves used by participants of a dialogue such as making arguments and counterarguments, claiming, challenging, and conceding or retracting a proposition. Prakken's (2006) categorization of moves is applicable in describing the rater moves such as "providing grounds for a claim, asking for the other rater's claim, etc." More detailed discussion on the integration of argumentation theory into rater discrepancy resolutions is presented in Author (2018). We analyzed the argumentative moves in score negotiations for discrepancy resolution using the framework summarized above so that we could identify how raters construct their claims and how they support them, especially whether their claims are supported by evidence.

\section{Methods}

The current study adopted a mixed method approach in that it involved the collection and interpretation of both qualitative and quantitative data. The overall design can be described as "Sequential Exploratory Data Collection and Analysis" since it required obtaining results from one inquiry in order to be able to investigate the other (Creswell, 2009).

\subsection{Setting}


This study was conducted at the English Preparatory School of a foundation university in Turkey. The language of instruction in this university is English (EFL); therefore, the students enrolled at the university are expected to have an upper-intermediate (B2) level of proficiency in English to be considered eligible for their departmental studies. A language proficiency exam is administered at the beginning of each academic year to sort out the incoming students who are eligible to study in their departments from those who will be required to study at the English Preparatory School. Students have to pass a module-exit exam at B2 level in order to go to faculty at the end of an academic year. An analytic rating scale out of 20 is used to assess the written component of the module exit exam. The pass/fail cut-score is 12 out of 20.

Discrepancies, in other words, inconsistent scores assigned to the same essay, are not uncommon in this setting. In principle, two conditions create discrepancy between the raters: a score difference higher than two in a scale of 20 and a discrepancy in a pass/fail decision. In cases of rater discrepancy, the raters meet for a discrepancy resolution negotiation. Many cases are resolved through rater discussion. If the raters fail to agree upon a score, the essay is scored by a third rater, the level coordinator, and the final score the essay is given depends on the coordinator's judgment.

\subsection{Participants}

The participants of this study are instructors of English at the above-mentioned English Preparatory School with teaching experience ranging from two to 25 years. All of the participants are familiar with the analytic rating scale and have experience in teaching and scoring B2-level writing. The instructors $(\mathrm{N}=30)$ participated in different phases of the study as essay raters or scheme coders.

\subsection{Instrument and instrument design}


The developmental steps in the creation of the Rater Negotiation Scheme (RNS) (see Table 3) were as follows:

a) Selection of essays (Phases 0 and 1): student essays which caused rater discrepancy were selected among the output of an already administered and scored exam;

b) Recording rater negotiations (Phase 2): the selected essays were re-scored by a team of participants, and where there were score differences, their discrepancy negotiations were audiorecorded.

c) Analysis and coding: The audio recordings of rater discrepancy negotiations were analyzed and coded in a recursive manner by two coders to identify the rater moves, and as a result, a Rater Negotiation Scheme (RNS) with move categories was developed.

d) Validating the RNS (Phases 3 \& 4): the newly developed RNS was validated through the field-testing of the rater moves under authentic rater negotiation settings.

In Phase 2, 13 raters scored 17 essays that were scored inconsistently in the previous phase. All raters scored all the essays and the agreement among these raters was calculated on SPSS using intraclass correlation coefficient two-way random consistency (same essays, random population of raters) (Shrout \& Fleiss, 1979). The results showed high general internal consistency measures (13 raters; $\alpha=.95)$. This was done as a check of the reliability of scoring before the study proceeded. 13 essays produced discrepant scores. This meant 26 negotiation sessions were recorded. Out of 26 transcripts, the first 10 transcripts were studied by the researchers together in order to identify argumentative moves and develop the categories of the scale.

In deciding on the moves to include in the RNS, two of the principles employed by Cumming (1990) in his categorization of decision-making behaviors of individual raters were followed: representation of logically relevant and distinct cognitive behaviors; and occurrence with sufficient frequency based on rater reports (Cumming, 1990, p.37). The agreed-upon categorizations formed 
the moves in the RNS. It was of paramount importance to write the move-descriptors clearly and support them with explanatory examples to avoid any overlapping categories (see Appendix). After the preliminary move categories of the RNS were formed, the researchers coded seven transcripts separately and compared their coding retrospectively for calibration purposes. The remaining nine transcripts were also coded separately by the two researchers to check for categorization accuracy. At every phase of this process, the researchers discussed the RNS, and revised and refined the categories. During this recursive scheme development phase, the researchers had three purposes in mind:

- to identify the argumentation moves as accurately as possible to reflect the thinking processes of the raters;

- to eliminate any overlapping move or any category that did not seem to produce meaningful results; and

- to make the Rater Negotiation Scheme as user friendly as possible.

To this end, the terminology used throughout the RNS was revised and standardized following the definitions of move (Walton, 2005); claim, ground data, backing (Toulmin, 1958), and the verbs which define what we do with the moves to concede, retract, accept, and refuse (Prakken, 2006).

Phase 3 included data collection under authentic exam settings for field testing, which would be done in Phase 4. The field testing focused on two issues. The first was to check whether the rater moves listed in the RNS are also viable in coding the data collected in an authentic context.

Secondly and more importantly, was whether the RNS in its refined form could be used reliably on authentic data by trained coders other than the researchers developing the scheme. This would give construct validity evidence to a newly developed scheme for the analysis of an unexplored issue. Before the field test, a training pack consisting of the third draft of the RNS with move descriptors 
and examples, three coding exercises (one to build familiarity, another one to confirm the understanding of the move categories and the third one to check the consistency of the coding by the newly trained coders) were prepared and given to the five participants who would act as coders in the field testing. Individual feedback was provided at the end of each exercise to the coders. This constituted Coder Training- Part 1 and the overall coder-key agreement percentage at the end of this session was calculated as $61 \%$ with a range of $44 \%$ to $72 \%$. This indicated that the coder training was not completed yet and some improvements were needed. Further explanation and exercises were provided to the coders and the Rater Negotiation Scheme was further revised in the light of the observations from this training session. The new coder training pack with the revised version of the RNS included the new form of move descriptors, additional notes to the coders where mostly confused move codes were explained and their differences were clarified, and a new exercise. In this session, the coders showed $82 \%$ overall key agreement.

In the field test, the coders were given five new transcripts of rater negotiation sessions which were recorded during authentic exam score discrepancy discussions and they were allowed 10 days to finish the coding. These five negotiation sessions used in the field test were chosen among the rater discussions which lasted longer than five minutes, and in which two rater scores differed the most. At the end of the coding of each transcript, the coders were requested to send their answers to the researchers. During the 10-day-time period allocated for the field test, several one-on-one researcher-coder feedback sessions were held whenever either party felt the necessity for it. At the end of the field test, the overall coder-key agreement was $89 \%$.

\subsection{Summary of procedures}

Due to the complex nature of the process, making a summary of the procedures followed in the development of the Rater Negotiation Scheme (RNS) might prove useful. (see Table 1). While the 
number of participants $(\mathrm{N})$ changed in every phase, the total number of participants was 30 . This was because some participants took part in several phases.

\section{Table 1.}

Phases of Rater Negotiation Scheme development

\begin{tabular}{|c|c|c|c|c|}
\hline Phase & $\mathbf{N}$ & $\begin{array}{c}\text { Participants' } \\
\text { Action }\end{array}$ & Researchers' action & Research aim \\
\hline Phase 0 & 25 & $\begin{array}{l}\text { Scored } 235 \\
\text { essays in B2 } \\
\text { exit exam. }\end{array}$ & $\begin{array}{l}\text { Obtained the submitted } \\
\text { scores } \\
\text { Compared the two raters' } \\
\text { scores } \\
\text { Identified } 95 \text { essays with } \\
\text { discrepant scoring }\end{array}$ & $\begin{array}{l}\text { To collect authentic data } \\
\text { in order to identify } \\
\text { student essays with } \\
\text { discrepant scores. }\end{array}$ \\
\hline Phase 1 & 6 & $\begin{array}{l}\text { Re-scored } 95 \\
\text { essays. }\end{array}$ & $\begin{array}{l}\text { Re-scored all } 95 \text { essays. } \\
\text { Compared scores assigned } \\
\text { to the same essay. } \\
\text { Identified } 17 \text { essays that } \\
\text { still showed discrepant } \\
\text { results. }\end{array}$ & $\begin{array}{l}\text { To filter essays which } \\
\text { again received discrepant } \\
\text { scores in re-scoring. }\end{array}$ \\
\hline Phase 2 & 13 & $\begin{array}{l}\text { Re-scored } 17 \\
\text { essays and } \\
\text { audiotaped their } \\
\text { rater } \\
\text { negotiations } \\
(\# 26) \text {. }\end{array}$ & $\begin{array}{l}\text { Identified } 13 \text { essays that } \\
\text { showed discrepant results } \\
\text { again. Asked the raters of } \\
\text { the highest two and the } \\
\text { lowest two scores to come } \\
\text { together for score } \\
\text { resolution and record their } \\
\text { discussion. } \\
\text { The audio recordings were } \\
\text { analyzed by two coders to } \\
\text { identify the rater moves. }\end{array}$ & $\begin{array}{l}\text { To filter essays which } \\
\text { again received discrepant } \\
\text { scores in second re- } \\
\text { scoring. } \\
\text { To transcribe and code the } \\
\text { rater negotiations (under } \\
\text { research settings) on these } \\
\text { essays in order to form the } \\
\text { RNS. }\end{array}$ \\
\hline Phase 3 & 25 & $\begin{array}{l}\text { Scored B2 exit } \\
\text { essays and } \\
\text { discussed } \\
\text { discrepant } \\
\text { scores with }\end{array}$ & $\begin{array}{l}\text { Obtained B2 level exit } \\
\text { exam results from Testing } \\
\text { Office on the exam day. } \\
\text { Identified } 73 \text { essays with }\end{array}$ & $\begin{array}{l}\text { To collect authentic data } \\
\text { for field-testing the } \\
\text { RNS(rater discrepancy } \\
\text { negotiations after an }\end{array}$ \\
\hline
\end{tabular}




\begin{tabular}{|c|c|c|c|c|}
\hline & & $\begin{array}{l}\text { another rater } \\
\text { within natural } \\
\text { exam } \\
\text { procedure. }\end{array}$ & $\begin{array}{l}\text { discrepant scoring } \\
\text { simultaneously. } \\
\text { Asked the raters' } \\
\text { permission to record their } \\
\text { negotiations for the field- } \\
\text { testing of the RNS. }\end{array}$ & exam). \\
\hline Phase 4 & 5 & $\begin{array}{l}\text { Received } \\
\text { training on the } \\
\text { use of the RNS } \\
\text { (Part } 1 \text { and } 2 \text { ), } \\
\text { and coded } 5 \\
\text { transcribed, } \\
\text { purposefully } \\
\text { selected rater- } \\
\text { negotiations } \\
\text { using RNS. }\end{array}$ & $\begin{array}{l}\text { Trained } 5 \text { participant raters } \\
\text { on the use of RNS and } \\
\text { provided constant } \\
\text { feedback during their } \\
\text { coding process. } \\
\text { Revised and improved the } \\
\text { RNS }\end{array}$ & $\begin{array}{l}\text { To investigate the } \\
\text { reflection of enlisted rater } \\
\text { moves in the RNS on } \\
\text { authentic settings. }\end{array}$ \\
\hline
\end{tabular}

\section{Results}

In this section, the results obtained from earlier and final phases of this study are presented. While the earlier phase refers to Phase 2 when the two researchers cooperated to code the rater negotiation transcripts and identify the rater moves, the final phase, namely Phase 4, supplies us with the results from the coding sessions when the coders worked on the field test (authentic exam setting) transcripts. The remaining phases did not present us with any results as their objective was data collection.

\subsection{RQ1. What are the discursive moves used by raters in score resolution discussions?}

At Phase 2, six categories of rater moves were defined : 1) Discussion management moves (D) The move category for actions and intentions of the raters to plan and manage the flow of their 
scoring procedure; 2) Claim related moves $(C)$ used when a rater puts forth an evaluative idea (claim) or inquires about it; 3 ) Acceptance related moves (A) indicating that the rater retracts his/her own claim; 4) Partial-acceptance moves (PA)used when the rater is not in full agreement with the other rater; 5) Refusal moves $(R)$ indicating disagreement with the other rater; and 6 ) Score negotiation moves $(S)$ used by the two raters in the process of reaching a mutual agreement about the score. It took eight months, several researcher meetings and scheme updates for this step to be completed, as explained above. After the rater (researchers') agreement percentages for the codings were calculated $(78 \%)$, the scheme was deemed ready for field testing.

At Phase 4, the task for the trained coders in the field test (teachers) was to code five raternegotiation dialogues (five coding tasks) using the latest version of the RNS. These dialogues were the transcripts of five rater discussions in which major discrepancies were observed and substantial discussions were held. First, the dialogues had been coded independently by the two researchers and a consensus key had been prepared. Trained coder-key agreement statistics for each task were calculated in percentages on Microsoft Excel 2016. Table 2 presents the tasks in the field test as 'Codings'. The first column is dedicated to the codings, and the second to the number of rater moves identified by the researchers in each rater negotiation session (No. of rater moves). Then come pairs of trained coder (TC) - key agreement columns. The first column in each TC pair shows the number (\#) of trained coder-key agreement for each coding, and the latter gives this number in percentages (\%). The last column presents the percentage of agreement for each coding. At the end of the field test, the overall trained coder-key agreement was $89 \%$. 


\section{Table 2.}

Field Test: Trained coder (TC)-key agreement analysis summary

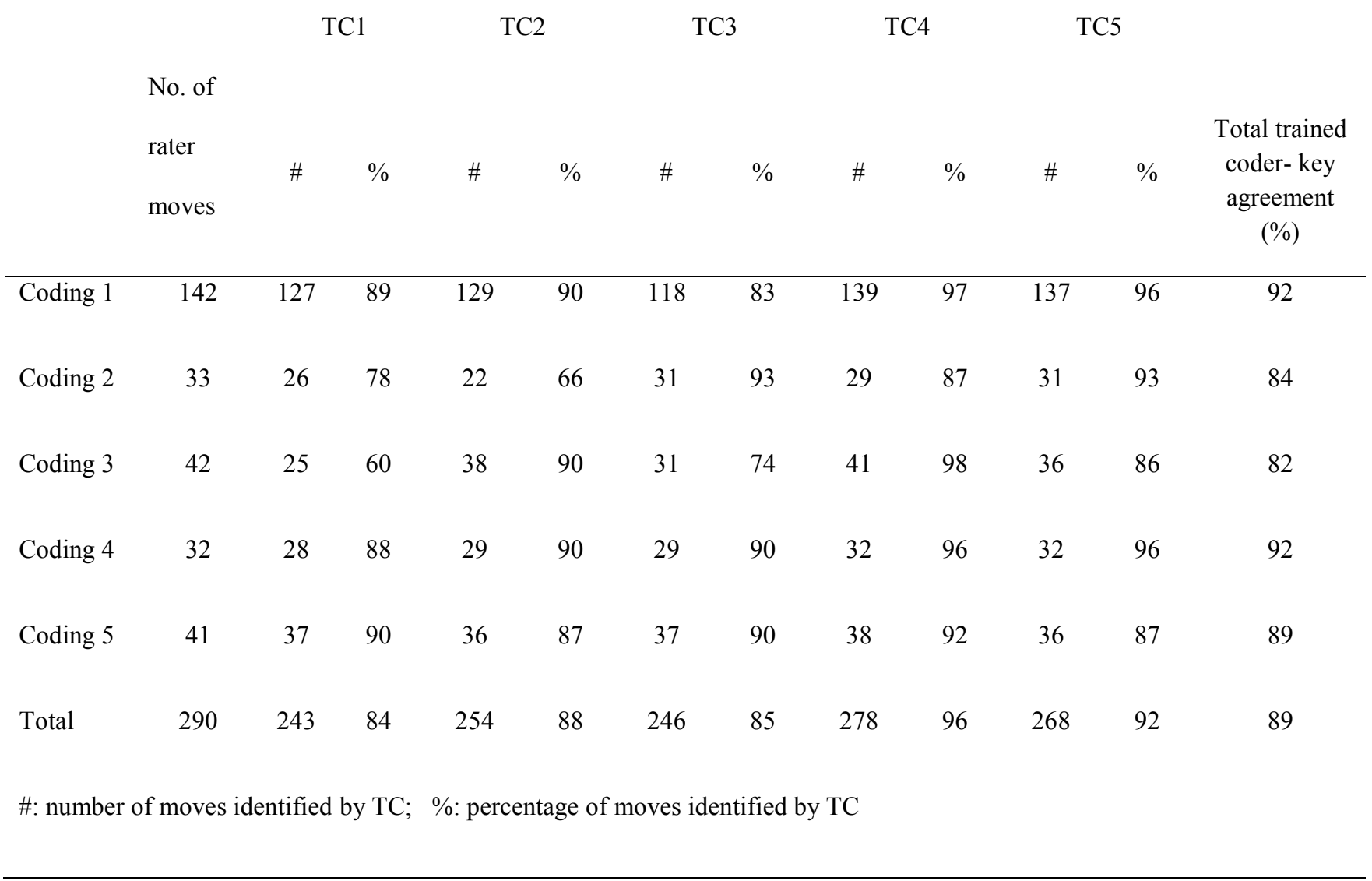

Further refinement took place after the field testing of RNS. The overall results showed that in rater negotiations some of the rater moves listed in the RNS were used more frequently than others while some moves, as presented in detail in the discussion section, were not observed in authentic settings. Furthermore, following the validation stage, it was observed that some moves and move categories that had been included in the RNS could not be used efficiently. After extensive discussion and feedback by the trained coders, the researchers decided either to remove them from the RNS or to merge them into other categories. These will be discussed in detail after the discussion of the second research question, which focuses on the comparison of the results from the research and field test settings. This is done to facilitate the ease of reference to the numbers in 
Table 6 for the reader. All in all, having gone through these refinement stages, we can claim that RNS now includes genuinely existing, easily identifiable and valid categories of the moves that appear in rater negotiations. Following the omission of some moves and move categories, the moves included in the Rater Negotiation Scheme were re-numbered to provide practicality in its future use (see Table 3).

Table 3.

The Rater Negotiation Scheme (RNS)

\begin{tabular}{|c|c|c|c|c|}
\hline $\begin{array}{l}\text { MANAGING } \\
\text { THE } \\
\text { DISCUSSION } \\
\text { (D) }\end{array}$ & $\begin{array}{l}\text { CLAIM RELATED } \\
\text { MOVES (C) }\end{array}$ & $\begin{array}{l}\text { ACCEPTANCE } \\
\text { MOVES (A) }\end{array}$ & $\begin{array}{l}\text { REFUSAL } \\
\text { MOVES (R) }\end{array}$ & $\begin{array}{c}\text { SCORE } \\
\text { NEGOTIATION } \\
\text { MOVES (S) }\end{array}$ \\
\hline \multirow[t]{5}{*}{$\begin{array}{l}\text { D1. Deciding } \\
\text { how to read and } \\
\text { negotiate (how } \\
\text { to proceed) }\end{array}$} & C1. Making a claim & $\begin{array}{l}\text { A1. Accepting the } \\
\text { other rater's claim }\end{array}$ & $\begin{array}{l}\text { R1. Nullifying or } \\
\text { questioning the } \\
\text { other rater's claim } \\
\text { (aligned) }\end{array}$ & $\begin{array}{l}\text { S1. Negotiating the } \\
\text { score by } \\
\text { a. pulling towards } \\
\text { one's own score } \\
\text { b. moving towards } \\
\text { the other rater's } \\
\text { score }\end{array}$ \\
\hline & $\begin{array}{l}\text { C2. Providing the } \\
\text { grounds for one's own } \\
\text { claim by referring to the } \\
\text { a. essay } \\
\text { b. scale } \\
\text { c. language criteria in } \\
\text { target context (faculty) } \\
\text { d. other criteria }\end{array}$ & $\begin{array}{l}\text { A2. Admitting } \\
\text { one's own mistaken } \\
\text { claim }\end{array}$ & $\begin{array}{l}\text { R2. Stating an } \\
\text { alternative } \\
\text { counter-argument } \\
\text { (non-aligned) }\end{array}$ & $\begin{array}{l}\text { S2. Stating } \\
\text { resolution }\end{array}$ \\
\hline & $\begin{array}{l}\text { C3. Asking for the other } \\
\text { rater's claim }\end{array}$ & $\begin{array}{l}\text { A3. Providing } \\
\text { grounds for one's } \\
\text { own mistaken } \\
\text { claim }\end{array}$ & $\begin{array}{l}\text { R3. Stating } \\
\text { commitment to } \\
\text { one's own claim }\end{array}$ & $\begin{array}{l}\text { S3. Blocking } \\
\text { resolution / stating } \\
\text { non-resolution }\end{array}$ \\
\hline & $\begin{array}{l}\text { C4. Asking for the } \\
\text { grounds of the other's } \\
\text { claim }\end{array}$ & $\begin{array}{l}\text { A4. Providing } \\
\text { grounds for the } \\
\text { other rater's claim }\end{array}$ & & \\
\hline & $\begin{array}{l}\text { C5. Hesitating / } \\
\text { questioning one's own } \\
\text { claim. }\end{array}$ & & & \\
\hline
\end{tabular}




\subsection{RQ2. Does the nature of score negotiation differ according to the context?}

Setting plays a role in any communication. It should be noted that the rater negotiation discussions used in the field test were recorded in situ, right after a B2 Level module exit examination, and they were dramatically different from those recorded under research settings. Under genuine exam conditions, the raters had a very limited time to discuss the discrepancies with their partners due to the high number of rater negotiations they needed to participate in.

\subsubsection{Duration of rater discussions}

Although it was possible to observe the rater negotiation moves in authentic settings, most of these negotiations did not last long. More than half of the 73 rater negotiations recorded in authentic settings started and finished with immediate agreement between the raters. More precisely, 24 of the recorded discussions lasted less than 59 seconds, 29 of them were resolved within three to five minutes without any substantial discussion, and only in 20 discussions did it take longer than five minutes to reach a resolution. The distribution of the discussions recorded under research settings $(\mathrm{n}=26)$ into the three time categories mentioned above was dramatically different; zero, seven, and 19 respectively (see Table 4). This was a good indicator of how different rater negotiations could be in authentic contexts.

\section{Table 4.}

Time duration for rater discrepancy negotiations

\begin{tabular}{lccc}
\hline \multicolumn{1}{c}{ Setting for Data Collection } & $0-2$ min 59 secs & 3 mins -4.59 secs & 5 mins - .. \\
\hline Research Settings (N=26) & 0 & $7(27 \%)$ & $19(73 \%)$ \\
Authentic post-exam settings & $24(33 \%)$ & $29(40 \%)$ & $20(27 \%)$ \\
(field test) $(\mathrm{N}=73)$ & & &
\end{tabular}




\subsubsection{Context-dependent move variety}

The frequency of each rater move in the RNS was also calculated using Microsoft Excel 2016. Table 5 below shows the frequency and the percentage of each RNS move under research (RS) and field test (FT) conditions and gives the coding accuracy for each move in the field test. This analysis includes nine dialogues from research setting, which were coded by the researchers independently, and five dialogues from the field test. The total number of the moves for nine dialogues recorded under research settings was 562, while this number was 285 for the five dialogues recorded under authentic settings.

\section{Table 5.}

Move frequency in rater negotiations

\begin{tabular}{|c|c|c|c|c|c|c|c|}
\hline & & \multicolumn{2}{|c|}{ Frequency } & \multicolumn{2}{|c|}{$\begin{array}{l}\text { Percentage of } \\
\text { moves }\end{array}$} & \multicolumn{2}{|c|}{ Field Test } \\
\hline & & R.S. & F.T. & R.S. & F.T. & $\begin{array}{l}\text { Possible } \\
\text { no. of } \\
\text { codings }\end{array}$ & $\begin{array}{l}\text { Coding } \\
\text { accuracy }\end{array}$ \\
\hline D1 & Deciding how to read and negotiate & 10 & 4 & $1.8 \%$ & $1.4 \%$ & 20 & $95 \%$ \\
\hline $\mathrm{C} 1$ & Making a claim & 66 & 28 & $11.7 \%$ & $9.9 \%$ & 140 & $96.4 \%$ \\
\hline $\mathrm{C} 2 \mathrm{a}$ & $\begin{array}{l}\text { Providing the grounds for one's } \\
\text { own claim by referring to the essay }\end{array}$ & 130 & 66 & $23.1 \%$ & $23.3 \%$ & 330 & $92.4 \%$ \\
\hline $\mathrm{C} 2 \mathrm{~b}$ & $\begin{array}{l}\text { Providing the grounds for one's } \\
\text { own claim by referring to the scale }\end{array}$ & 5 & 7 & $0.8 \%$ & $2.5 \%$ & 35 & $94.3 \%$ \\
\hline $\mathrm{C} 2 \mathrm{c}$ & $\begin{array}{l}\text { Providing the grounds for one's } \\
\text { own claim by referring to future } \\
\text { studies }\end{array}$ & 2 & 6 & $0.3 \%$ & $2.1 \%$ & 30 & $93.3 \%$ \\
\hline $\mathrm{C} 2 \mathrm{~d}$ & $\begin{array}{l}\text { Providing the grounds for one's } \\
\text { own claim by referring to other } \\
\text { criteria }\end{array}$ & 0 & 2 & $0 \%$ & $0.7 \%$ & 10 & $80 \%$ \\
\hline $\mathrm{C} 3$ & Asking for the other rater's claim & 12 & 19 & $2.1 \%$ & $6.7 \%$ & 95 & $94.7 \%$ \\
\hline $\mathrm{C} 4$ & $\begin{array}{l}\text { Asking for the grounds of the } \\
\text { other's claim }\end{array}$ & 3 & 2 & $0.5 \%$ & $0.7 \%$ & 10 & $100 \%$ \\
\hline C5 & $\begin{array}{l}\text { Hesitating / Questioning one's own } \\
\text { claim }\end{array}$ & 14 & 4 & $2.5 \%$ & $1.4 \%$ & 20 & $85 \%$ \\
\hline A1 & Accepting the other rater's claim & 48 & 11 & $8.5 \%$ & $3.9 \%$ & 55 & $87.3 \%$ \\
\hline A2 & $\begin{array}{l}\text { Admitting one's own mistaken } \\
\text { claim }\end{array}$ & 20 & 10 & $3.5 \%$ & $3.5 \%$ & 50 & $96 \%$ \\
\hline A3 & Providing grounds for own & 10 & 3 & $1.8 \%$ & $1.1 \%$ & 15 & $86.7 \%$ \\
\hline
\end{tabular}




\begin{tabular}{|c|c|c|c|c|c|c|c|}
\hline & mistaken claim & & & & & & \\
\hline $\mathrm{A} 4 \mathrm{a}$ & $\begin{array}{l}\text { Providing grounds for the other } \\
\text { rater's claim by referring to the } \\
\text { essay }\end{array}$ & 55 & 18 & $9.7 \%$ & $6.4 \%$ & 90 & $91.1 \%$ \\
\hline $\begin{array}{l}A 4 b \\
* *\end{array}$ & $\begin{array}{l}\text { Providing grounds for the other } \\
\text { rater's claim by referring to the } \\
\text { scale }\end{array}$ & 4 & 0 & $0.7 \%$ & $0 \%$ & 0 & $0 \%$ \\
\hline $\begin{array}{l}A 4 c \\
* *\end{array}$ & $\begin{array}{l}\text { Providing grounds for the other } \\
\text { rater's claim by referring to target } \\
\text { context }\end{array}$ & 0 & 0 & $0 \%$ & $0 \%$ & 0 & $0 \%$ \\
\hline $\begin{array}{l}A 4 d \\
* *\end{array}$ & $\begin{array}{l}\text { Providing grounds for the other } \\
\text { rater's claim by referring to other } \\
\text { criteria }\end{array}$ & 1 & 2 & $0.1 \%$ & $0.7 \%$ & 10 & $50 \%$ \\
\hline $\begin{array}{l}P A \\
*\end{array}$ & $\begin{array}{l}\text { Accepting a part of a claim but } \\
\text { generating counter-claims for the } \\
\text { rest in the negotiation }\end{array}$ & 26 & 9 & $4.6 \%$ & $3.2 \%$ & 45 & $66.6 \%$ \\
\hline $\mathrm{R} 1$ & $\begin{array}{l}\text { Nullifying the other rater's claim } \\
\text { (aligned) }\end{array}$ & 36 & 23 & $6.4 \%$ & $8.1 \%$ & 115 & $84.3 \%$ \\
\hline $\mathrm{R} 2$ & $\begin{array}{l}\text { Stating an alternative counter- } \\
\text { argument (non-aligned) }\end{array}$ & 4 & 4 & $0.7 \%$ & $1.4 \%$ & 20 & $80 \%$ \\
\hline $\mathrm{R} 4$ & $\begin{array}{l}\text { Stating commitment to one's own } \\
\text { claim }\end{array}$ & 29 & 24 & $5.1 \%$ & $8.5 \%$ & 120 & $76.7 \%$ \\
\hline R5 & Retracting acceptance & 2 & 4 & $0.3 \%$ & $1.4 \%$ & 20 & $70 \%$ \\
\hline S1a & $\begin{array}{l}\text { Negotiating the score by pulling } \\
\text { towards one's own score }\end{array}$ & 4 & 0 & $0.7 \%$ & $0 \%$ & 0 & $0 \%$ \\
\hline $\begin{array}{l}S 1 b \\
*\end{array}$ & $\begin{array}{l}\text { Negotiating the score by finding the } \\
\text { middle ground }\end{array}$ & 39 & 25 & $6.9 \%$ & $8.8 \%$ & 125 & $85.6 \%$ \\
\hline S1c & $\begin{array}{l}\text { Negotiating the score by moving } \\
\text { towards the other rater's score }\end{array}$ & 16 & 3 & $2.8 \%$ & $1.1 \%$ & 15 & $86.7 \%$ \\
\hline S3 & Stating resolution & 20 & 7 & $3.5 \%$ & $2.5 \%$ & 35 & $100 \%$ \\
\hline S4 & $\begin{array}{l}\text { Blocking resolution / Stating non- } \\
\text { resolution }\end{array}$ & 6 & 2 & $1 \%$ & $0.7 \%$ & 10 & $100 \%$ \\
\hline
\end{tabular}

* omitted ;**collapsed under the main category

The results enable a comparison of the similarities and differences between the move frequencies in dialogues recorded under research settings and authentic settings. To begin with, the most frequently used rater move in both settings was ' $\mathrm{C} 2 \mathrm{a}$ : Providing the grounds for one's own claim by referring to the essay'. Approximately $23 \%$ of the total rater moves in each setting were 
$\mathrm{C} 2 \mathrm{a}$. The second most frequent move in both settings was ' $\mathrm{C} 1$ : Making a claim', which basically refers to the statement of the score given to the essay.

On the other hand, the percentages of some moves varied according to the setting of the rater negotiation. One of these moves was ' $\mathrm{C} 3$ : Asking for the other rater's claim.' While this move had a percentage of $2.1 \%$ among the moves identified under research settings, it had $6.7 \%$ of the total moves identified under authentic settings. Another move that showed variance in its percentages across the research settings was 'A1: Accepting the other rater's claim.' The percentage for the use of this move was much higher under research settings ( $8.5 \%)$ compared to authentic settings (3.9 \%). Similarly, the percentage for the rater move 'A4a: Providing the grounds for the other rater's claim by referring to the essay' was higher under research settings $(9.7 \%)$ than under authentic settings $(6.4 \%)$.

\subsubsection{Ghost moves}

'Ghost moves' can be defined as rater moves which were identified under research settings but disappeared under authentic settings. The least frequent moves used in rater negotiations had a percentage of less than one percent of the total moves in at least one of the settings. Having observed the results, it was an immediate decision of the researchers to omit the following four moves from the RNS: 'A4b: Providing the grounds for the other rater's claim by referring to the scale', 'A4c: Providing the grounds for the other rater's claim by referring to the language criteria in future studies (faculty), 'A4d: Providing the grounds for the other rater's claim by referring to other criteria', 'R5: Retracting acceptance'. These moves were omitted not only due to low frequency, but also low coding accuracy (Cumming, 1990), as well as the participants' comments during the researcher-participant feedback sessions that they might be confusing. The first three among these moves were collapsed and collected under their main category, 'A4: Providing the grounds for the other rater's claim, and R5 was completely omitted. 
Another move category the researchers deleted from the list of rater moves was 'PA: Showing partial agreement'. Despite its high level of frequency, especially in rater negotiations recorded under research settings, this move category was not clearly identifiable by the coders with a low coding accuracy of $66.6 \%$ percent. This move was usually characterized by acceptance of one positive characteristic of the essay but then pointing out a weakness and this usually corresponded to sequences of 'A1 + C2a', 'A1 + R1', 'A1 + R4', 'A4a + R1', and 'C2a+ A4a' moves.

Another reportedly confusing move category was the S1 category through which the two raters negotiate the score. The researchers' first observation of this was that the raters were negotiating the score in three ways: a) one rater pulls the score towards her own score, b) the two raters find a middle way, and c) one rater carries her own score towards the other rater's score. The results show that 'S1a: Negotiating the score by pulling towards one's own score' was not sufficiently

represented in the rater dialogues. Having evaluated the participant feedback on this move category, the researchers decided to omit the second move, which was the natural outcome in all cases, and sharpen the distinction between S1a and S1c. Therefore, 'S1b: Negotiating the score by finding the middle way', was omitted from the move category, and the other two moves 'S1a: Negotiating the score by pulling towards one's own score', and 'S1c: Negotiating the score by moving towards the other rater's score' showing two directions of the negotiated score were kept in the RNS.

\section{Discussion}

As discussed earlier, the theoretical framework that enabled us to understand how rater discrepancies are negotiated came from argumentation theories. An evaluation of the results in line with these theories enables a number of suggestions about rater negotiations.

To begin with, in the light of Toulmin's (1958) argument pattern, this study has classified rater negotiations as a form of argumentation in that they follow an argument pattern in which a claim is made, supported, challenged, and either accepted or rejected by the other party. Referring back to 
Hamblin's (1971) components of an argument: ground data, claim, warrant, and backing, it can be suggested that, in the case of rater negotiations, the ground data come from test taker essays. The data are evaluated based on the warrant, in our case, the writing scale. This can be called the most delicate process in score argumentation because, as suggested by Wolfe (1997), the rater has two different cognitive interpretations: one for the text, and another one for scoring. How the rater approaches scoring is by nature very closely related to the rubrics. How balanced the rater approaches the rubric categories, on the other hand, is a matter of rater awareness. In line with their level of awareness, the rater puts forward a claim about the test taker's performance and provides backing to their claim when need be.

Furthermore, the current study more specifically classifies rater negotiations as persuasion dialogues based on Walton's (2010) explanation that in this type of dialogues, two discussants try to persuade each other on an issue without consideration of any personal gain. In this study, an analysis of rater moves used in rater negotiations facilitated a closer inspection of this persuasion process through which two raters make various moves to persuade each other and eventually resolve discrepancies. Therefore, we can now claim that rater negotiations are a type of argumentation done for the purpose of persuasion and that they operationalize the moves that can be categorized under argumentation schemes. This perspective allows for evidence-based analysis of score negotiations: Score negotiations can be analyzed in terms of strengths of the claims for and against score interpretations and prevalence and variety of evidence brought in score discussions, for example, how closely essay features are used as evidence and to what extent performance descriptors in the scale are referred to.

In the field of language assessment, certain studies suggesting the use of rater negotiations as an effective method to resolve rater discrepancies were discussed earlier (Johnson et. al., 2005; Trace, 2017). However, the analysis of the inner dynamics of rater negotiations with the help of the RNS developed in this study raises some concerns about the validity of rater negotiations as a method for 
score resolution. It has been observed that the rater negotiations under research and authentic settings had different qualities in terms of their time duration and variety in moves.. Authentic negotiations were much shorter, the raters preferring to hear the other's claims quickly and accepting the other's score more readily. Under research settings, the raters rejected the other's claims and stated commitment to their claims relatively more frequently. Far fewer ground data and warrant are provided in the authentic negotiation setting. Such observations indicate that the coherence and completeness of raters' argumentation on their interpretation of observed performance can in fact be impacted by contextual factors.

Time pressure forced many of the raters to go for the middle score when there is no major discrepancy. In fact, the most significant difference between the simulated research and authentic field test settings was primarily about the amount of time the raters were able to dedicate to rater negotiations. While the first group was given a full work-day to record their discussions at their own pace, the field test group was actually racing against time to complete their procedural duties following the module-exit examination at their institution. Another factor affecting the differences of time durations between rater negotiations in two different settings could be about the nature of the essays. When making this comparison, it should be kept in mind that the essays scored under research settings were selected as a result of many rounds of scoring, in all of which the scores those essays received were discrepant. The rater discrepancy related to the field test setting, on the other hand, was created through only one round of scoring. While the investigation of the relationship between the length of rater negotiations and efficient scoring was not of immediate relevance in this study, it might be concluded that the time period allowed by the institution for discrepancy negotiations was limiting, and it did not match the time period the raters themselves decided to allocate for their discussions under research settings. 


\section{Conclusion}

The results of this study may provide insight for raters, test designers, and rater trainers about various aspects of rater negotiations. All in all, the Rater Negotiation Scheme provides us with five move categories and 20 validated argumentation moves used in rater negotiations to resolve discrepancy. The listed move categories might serve as a reference for studies interested in the dialogic interactions in persuasive arguments, not only within the framework of language assessment, but also related to any field studying argumentation. As for its specific use in language assessment, the Rater Negotiation Scheme might serve as a research tool to investigate the scoring decisions of individual raters as they interact in a rater discussion. Scores can have multiple interpretations and discrepancy is where raters need to provide strong backing for their interpretations. Many participants who took part in the validation process of the RNS reported that through the coding process of the rater discussions, they learned about other raters' different scoring approaches towards the scoring task. Developing an understanding of a variety of individual interpretations different from one's own might help a rater lower their bias and reshape their own approach towards more evidence-based scoring, as well as gain tolerance to any criticism about their own scoring practices. Raters might be trained to follow agreeable argumentation steps and work on data (essay characteristics, scale descriptors) to back up their decisions more carefully. They can also be trained to find counter examples to their own claims so that they can practice scoring from different points of view and they can substantiate their decisions with more data.

Needless to say, further studies on rater negotiations should be done to see whether we can capture the nature of negotiations with the proposed Rater Negotiation Scheme in more detail. Research may also attempt to trace further evidence for the reasons that some rater moves change frequency under research settings and authentic settings. At this point, it should be noted that there are also a number of studies investigating how the logic of argumentation might vary across 
cultures, especially deriving from the level of politeness the discussants show towards each other (Miller, 1987; Lewis, 2005; Shum \& Lee, 2013; Zhu, 2014). Further investigation of the issue might lead to the inauguration of a new line of research investigating the context-dependent, in a bigger picture, cross-cultural factors affecting rater negotiations for discrepancy resolution, which might produce important implications, not only for test administrators in general, but also for the use of the Rater Negotiaton Scheme in different contexts.

Another relationship that might be further investigated is the one between essay features and rater discrepancy. More focus might be placed on what kind of essay features lead to rater discrepancy in order to gain more insight about these features, which would greatly assist in tailoring training of raters.

All in all, this study enabled us to take a deeper look at the dynamics of rater negotiations: It has been possible to categorize rater negotiations as persuasive argumentation and to offer a scheme to facilitate further investigation of this score resolution method. It is our contention that this research will facilitate more studies that will broaden our understanding of essay scoring and discrepancy resolution per se. 


\section{References}

Author. (2018).

Barkaoui, K. (2010). Explaining ESL essay holistic scores: A multilevel modeling approach. Language Testing, 27(4), 515-535.

Chapelle, C. A. (2012). Validity argument for language assessment: The framework is simple. Language Testing, 29(1), 19-27.

Cumming, A. (1990). Expertise in evaluating second language compositions. Language Testing, 7(1), 31-51.

Creswell, J. W. (2009). Qualitative procedures. Research design: Qualitative, quantitative, and mixed methods approaches, 173-202.

Eckes, T. (2012). Operational rater types in writing assessment: Linking rater cognition to rater behavior. Language Assessment Quarterly, 9(3), 270-292.

Freedman, S. W., \& Calfee, R. C. (1983). Holistic assessment of writing: Experimental design and cognitive theory. Research on writing: Principles and methods, In Huot, B. (1990). The literature of direct writing assessment: Major concerns and prevailing trends. Review of Educational Research, 60(2), 237-263.

Hamblin, C.L. (1971). Mathematical models of dialogue. Theoria, 37: 130-155.

Johnson, R. L., Penny, J., Gordon, B., Shumate, S. R., \& Fisher, S. P. (2005). Resolving score differences in the rating of writing samples: Does discussion improve the accuracy of scores? Language Assessment Quarterly: An International Journal, 2(2), 117-146.

Kane, M. T. (2006). Validation. Educational measurement, 4(2), 17-64.

Kane, M. (2012). Validating score interpretations and uses. Language Testing, 29(1), 3-17.

Kane, M. T. (2013). Validating the interpretations and uses of test scores. Journal of Educational Measurement, 50(1), 1-73.

Lewis, D. M. (2005). Arguing in English and French asynchronous online discussion. Journal of pragmatics, 37(11), 1801-1818

Lumley, T. (2005). Assessing second language writing: The rater's perspective (Vol. 3). 
Messick, S. (1993). Foundations of validity: Meaning and consequences in psychological assessment. ETS Research Report Series, 1993(2).

Miller, M. (1987). Argumentation and cognition.

Prakken, H. (2006). Formal systems for persuasion dialogue. The knowledge engineering review, 21(2), 163-188.

Shrout, P. E., \& Fleiss, J. L. (1979). Intraclass correlations: uses in assessing rater reliability. Psychological bulletin, 86(2), 420.

Shum, W., \& Lee, C. (2013). (Im)politeness and disagreement in two Hong Kong Internet discussion forums. Journal of Pragmatics, 50(1), 52-83.

Toulmin, S. (1958). The Uses of Argument. Cambridge University Press: Cambridge.

Trace, J., Janssen, G., \& Meier, V. (2017). Measuring the impact of rater negotiation in writing performance assessment. Language Testing, 34(1), 3-22

Walton, D. N. (1989). Dialogue theory for critical thinking. Argumentation, 3(2), 169-184.

Walton, D. (2005). Argumentation methods for artificial intelligence in law. Springer Science \& Business Media.

Walton, D. (2010, August). Types of Dialogue and Burdens of Proof. In COMMA (pp. 13-24).

Walton, D. (2016). A dialogue system for evaluating explanations. In Argument Evaluation and Evidence (pp. 69-116). Springer, Cham.

Walton, D., \& Krabbe, E. C. (1995). Commitment in dialogue: Basic concepts of interpersonal reasoning. SUNY press. Chicago

Wolfe, E. W. (1997). The relationship between essay reading style and scoring proficiency in a psychometric scoring system. Assessing Writing, 4(1), 83-106.

Wolfe, E. W., Song, T., \& Jiao, H. (2016). Features of difficult-to-score essays. Assessing Writing, 27, 1-10.

Zhu, W. (2014). Managing relationships in everyday practice: The case of strong disagreement in Mandarin. Journal of Pragmatics, 64, 85-101. 
Appendix . Rater moves in RNS with examples

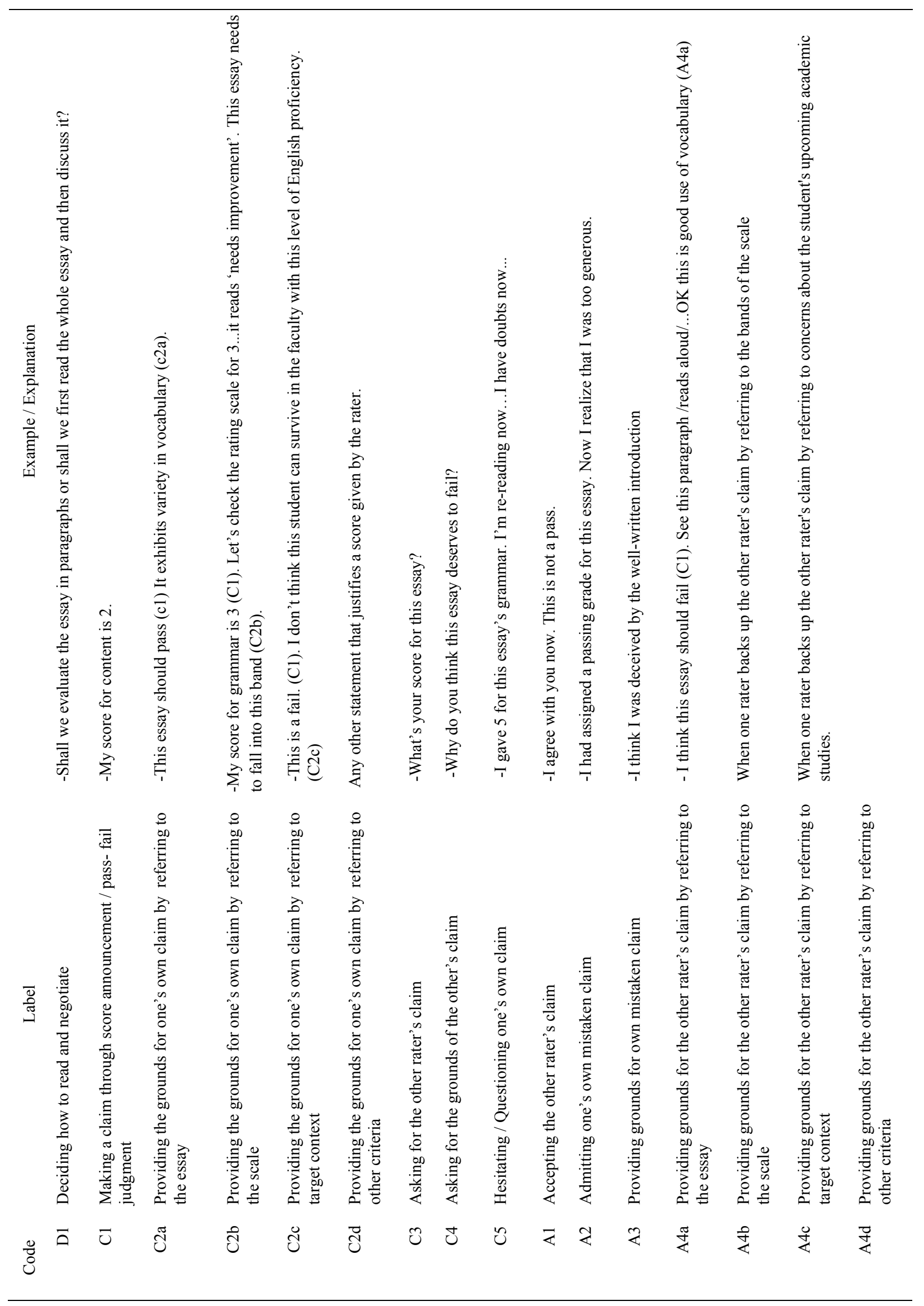




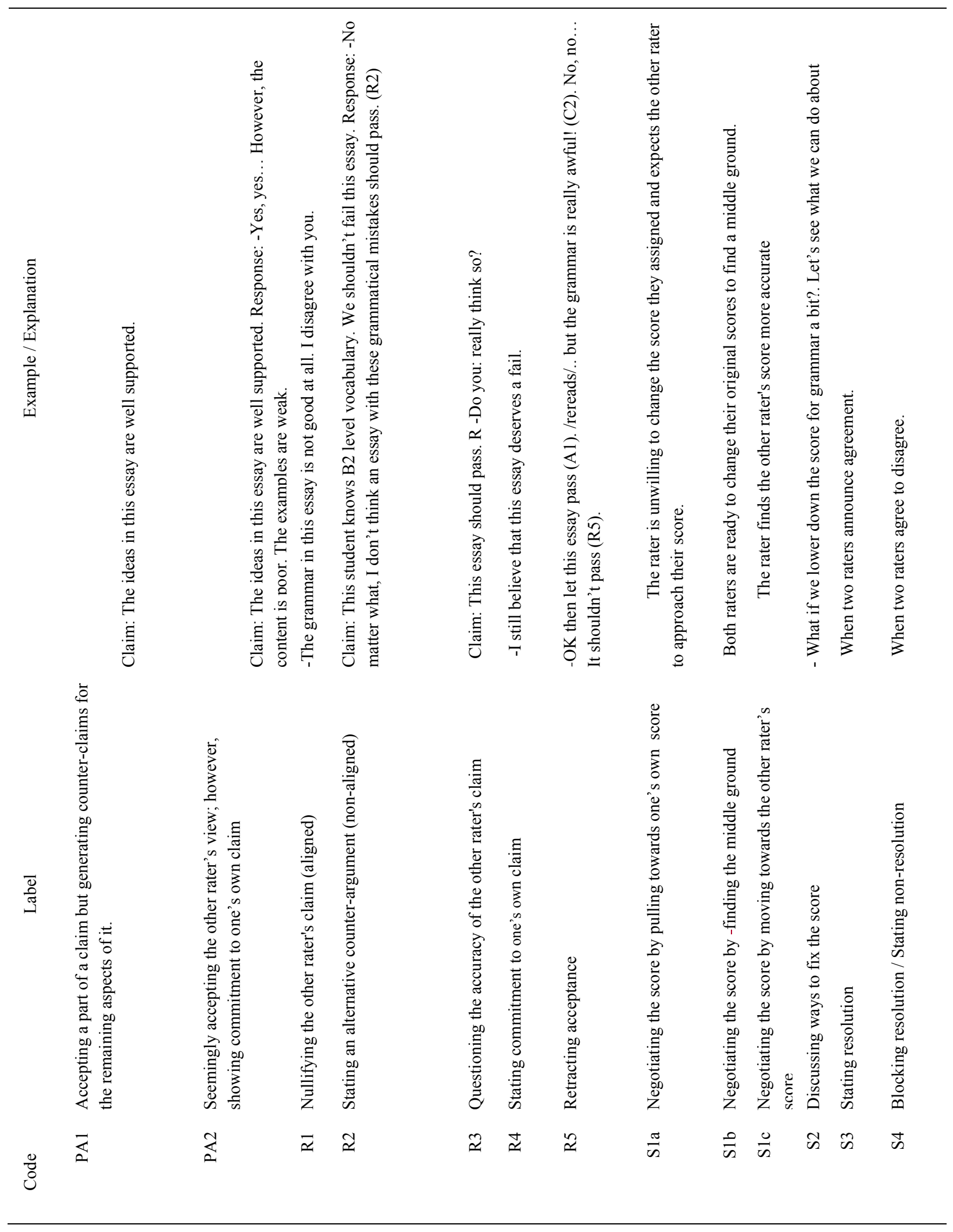




\section{Vitae}

Dr. Ece Sevgi-Sole holds a Ph.D. in Language Assessment from Yeditepe University. She has experience in teaching and testing academic writing, as well as training language teachers and running a university writing center. Currently, she is offering English language courses at University of Milan.

Assist. Prof. Aylin Ünaldı holds Ph.D.s in Language Assessment from Boğaziçi University and University of Bedfordshire. Currently, she is teaching at the School of Education and Professional Development at University of Huddersfield. Her main interests are teaching and assessment of L2 writing and reading at textual and multiple-text levels. 